\title{
Auditory Rehabilitation Post-Cochlear Implant
}

\author{
Diamante $\mathrm{G}^{1 *}$, Aranda $\mathrm{AL}^{2}$, Martinis $\mathrm{C}^{3}$, Bustingorry $\mathrm{F}^{4}$ and Gómez $\mathrm{A}^{4}$ \\ ${ }^{1}$ Professor for the Deaf, Gabriela Diamante Assistance Group, Argentina \\ ${ }^{2}$ Bachelor in Phonoaudiology, Del Salvador University, Argentina \\ ${ }^{3}$ Bachelor in Phonoaudiology, Argentinian Social Museum University, Argentina \\ ${ }^{4}$ Bachelor in Phonoaudiology, University of Buenos Aires, Argentina
}

\section{Research Article}

Volume 6 Issue 1

Received Date: April 28, 2021

Published Date: June 08, 2021

DOI: $10.23880 /$ ooaj-16000213

*Corresponding author: Gabriela Diamante, Professor for the Deaf, Master in Hearing and Language. Degree in Diagnosis and Neuropsychological Habilitation of Learning Disabilities. Director of GAG (Gabriela Diamante Assistance Group), Argentina, Tel: 05491151408652; Email: gabrieladiamante@hotmail.com

\section{Abstract}

Introduction: In the present work, a review is conducted on hearing loss, its origin, the consequences of the lack of a timely treatment, the possibilities and benefits provided by the access to a cochlear implant and the corresponding auditory rehabilitation.

Materials and Methods: The methods used in the present work were Ling Test, Vowel Recognition, Consonant Recognition, Two-syllable Word Test, and Open-set Sentence Recognition.

Results: By means of a descriptive study of a population that received a cochlear implant and after one year of use, we can observe high rates of auditory discrimination in all the variables presented and their levels of requirement and complexity, showing a close relationship between an appropriate and timely approach and a successful auditory rehabilitation.

Conclusion: In all of the cases in this sample, the cochlear implant led to an improved quality of life for both the patients and their family members, allowing children to develop the language and improve their performance in school activities, and adults to appropriately reintegrate into society.

Keywords: Hearing; Hearing Loss; Disability; Detection; Early Diagnosis; Early and Timely Intervention; Speech and Language Development

\section{Introduction}

Hearing loss is the most frequent congenital disability among newborns. The incidence of moderate hearing loss is 3 per 1000 newborns, and severe or profound hearing loss affects 1 in 1000 newborns [1]. There are innumerable conditions that cause profound hearing loss in the early phases of intra and extra-uterine life, which results in a lack of speech presentation [2]. It hinders oral language acquisition in a spontaneous and natural manner, severely compromising the learning process and the acquisition of reading and writing, putting people in a state of communicative isolation with the environment.

Its early detection, assessment, diagnosis and treatment (appropriate and timely) prevent serious linguistic and psychosocial repercussions. It is also important to identify real possibilities for quality-of-life improvement in adult patients who come late for consultation or have lost their hearing capacity for different reasons during the course of life. Currently, one in three people older than 60 years have some degree of decreased hearing, creating a greater dependence on the environment. The inability to communicate highly affects the cognitive processes, causing 


\section{Otolaryngology Open Access Journal}

changes in personality, depression, decreased functional status and loneliness [3].

The cochlear implants (CI) are high technology biomedical devices that electrically stimulate the remaining auditory nerve fibers to produce sound impressions in profound hearing-impaired people who obtain minimum benefits or none with the traditional types of amplification [4]. The access to a Cochlear Implant allows both children and adults to enter the world through hearing, as the implant works as a bypass replacing the dead regions in the cochlea and sending electrical impulses that coincide with the sound signals through the respective electrodes directly to the brain. In this way, it allows people to perceive sounds, identify sources of sound, and assign a meaning to them.

Regardless of the subjects' age and timing of implantation, which has an influence on the performance, all the subjects exhibit late improvements in relation to their pre- implant status. The possibility to access sound allows them to actively participate in an auditory environment, providing them benefits at the personal, family and social level [5]. It is noteworthy the importance of an auditory rehabilitation post-cochlear implant and the elaboration of an appropriate treatment plan.

In order to ensure the success of any auditory rehabilitation program, it is important that all of the activities, the dynamics and the progress of the child occur through the developmental hierarchies of auditory abilities, speech and language, communication and cognition [6]. The rehabilitation process usually employs two stimulation pathways, auditory and visual, by which activities of auditory training and hearing capacity will be carried out [7].

\section{Objective}

The main objective of this work is to describe the auditory rehabilitation process carried out in several age groups, showing their responses to different variables and degrees of complexity one year after the cochlear implantation. In this way, the aim is to discuss the importance of an early detection of hearing loss in order to favor access to an early approach tailored to the needs of each individual, to provide the appropriate equipment, and to conduct a subsequent follow-up and auditory stimulation.

\section{Materials and Methods}

The aim of the present work is to do a descriptive study of a hearing-impaired patient population who underwent a cochlear implant procedure as well as assessments of the degree of auditory discrimination post-procedure. The study population consists of a non-probabilistic, incidental sample of 44 patients in some of the tests and a subset of 25 patients in the others, with an age range between 6 and 86 years and an arithmetic mean of 37.5 years.

The group distribution of etiological factors, time from diagnosis to implant, and time from implant date to testing are shown. The aforementioned assessments consist of determining the degree of auditory discrimination, expressed as percentages, using the following tests: Ling Test, vowel lists, consonant lists, two-syllable word and sentence lists. All of them were administered in seven different settings: identification, whispered voice, while moving, with background noise, through a door, on the phone and through the intercom.

\section{Ling Test}

This is a formal speech-perception test developed by Dr. Daniel Ling in 1989 that can be administered since the early life. According to the type of responses received, the Ling Test can be considered a detection test or a recognition test. When dealing with babies or children with no previous auditory experience, detection is more feasible, either in a conditioned manner or by observation; however, depending on their chronological age, the repetition of heard sounds can be achieved, providing information about their ability to identify phonemes.

The therapist produces sounds aloud at different distances $(30 \mathrm{~cm}, 1$ and $3 \mathrm{~m})$, which represent the sound spectrum of speech. The chosen sounds are $/ \mathrm{a} /, / \mathrm{i} /, / \mathrm{u} /, / \mathrm{m} /$, /s/sh/, which represent significant cues in each frequency band that cover the speech spectrum. If the child can detect them, it means that he/she is capable of discriminating the sounds of the spoken language.

\section{Matrix of Isolated Vowel Recognition}

Random presentation of isolated vowels, allowing to visualize quickly and effectively the patient's ability to identify them, as well as the substitutions or confusions that he/she exhibits.

\section{Matrix of Consonant Recognition: Medial}

As with vowel matrices, consonant matrices are used to obtain analytical information about the ability to perceive these phonemes outside the facilitating context of semantics. Each consonant is presented randomly.

\section{Two-syllable Word Lists}

Assessment of auditory perception using the set of 25 phonetically-balanced two- syllable words from the A1 list by Dr. Tato. 


\section{Open-set Sentence Lists}

The main goal is to assess speech perception using simple sentences and plain vocabulary. The words that are used are not phonetically balanced, but they bear relation to their total number in each list, including articles, nouns, verbs, adjectives, prepositions and adverbs.

\section{Study Group Description}

The study population consists of a non-probabilistic, incidental sample of 44 patients in some of the tests performed, and a subgroup of 25 subjects in others, with an age range between 6 and 86 years and an arithmetic mean of
37.5 years.

\section{Results}

The results of the auditory discrimination tests of the total 44 patients are expressed as percentages, taking into account the different forms and degrees of complexity. In general, the results of all patients in the five tests (Table 1 \& Figures $1 \mathrm{a}, 1 \mathrm{~b}$ ) show an average auditory discrimination rate of $76 \%$, considering all six levels of complexity. In the case of the last two complexity formats (on the phone and through the intercom), a decrease is evident with an average of $63 \%$ in all variables.

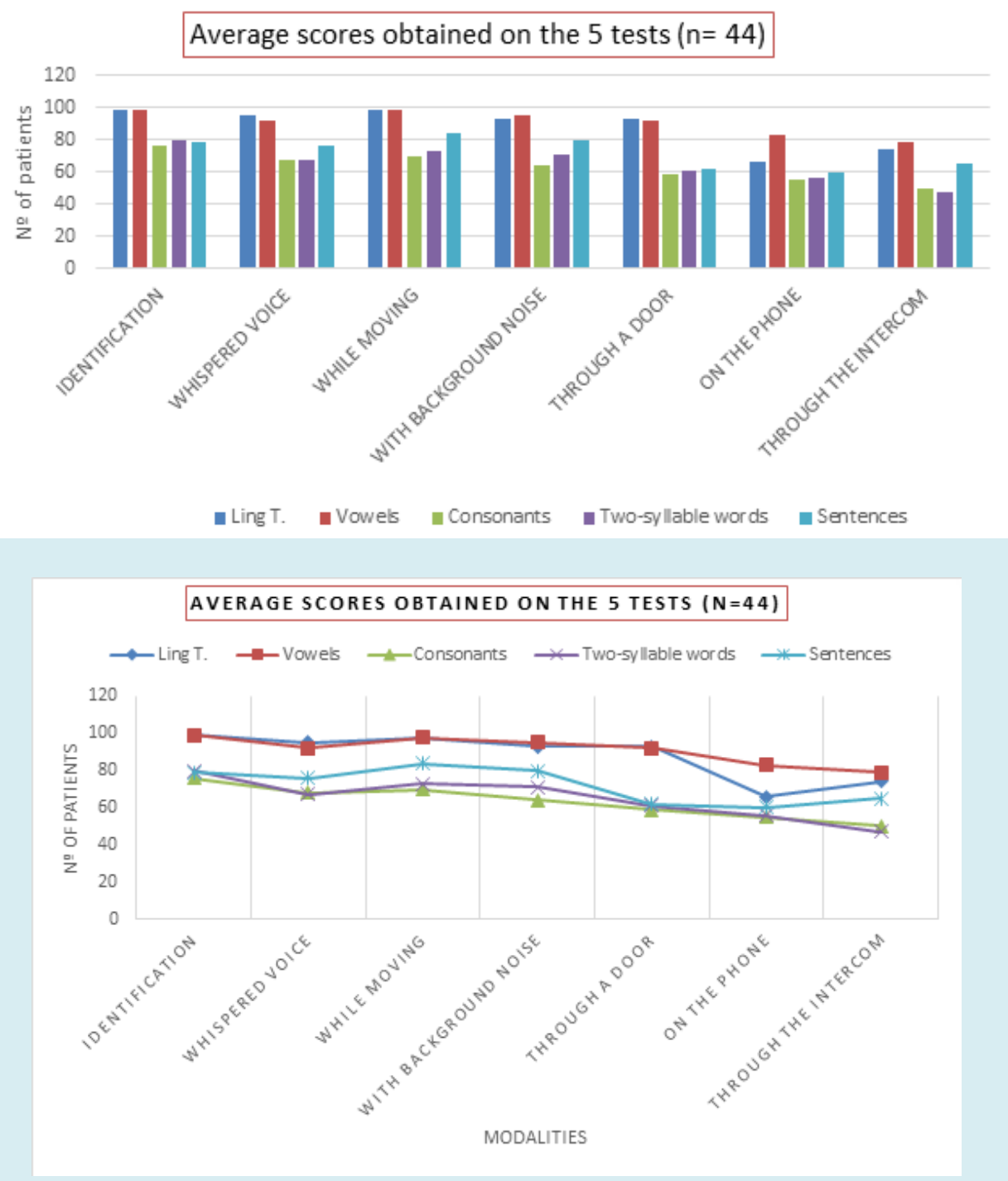

Figures 1a \& 1b: Average results of all patients. 


\section{Otolaryngology Open Access Journal}

\begin{tabular}{|c|c|c|c|c|c|}
\hline & Ling T. & Vowels & Consonants & Two-syllable words & Sentences \\
\hline Identification & 99 & 99 & 76 & 80 & 79 \\
\hline Whispered Voice & 95 & 92 & 68 & 67 & 76 \\
\hline While Moving & 98 & 98 & 70 & 73 & 84 \\
\hline With Background Noise & 93 & 95 & 64 & 71 & 80 \\
\hline Through A Door & 93 & 92 & 59 & 61 & 62 \\
\hline On The Phone & 66 & 83 & 55 & 56 & 60 \\
\hline Through The Intercom & 74 & 79 & 50 & 47 & 65 \\
\hline
\end{tabular}

Table 1: Average results of all patients on the 5 tests $(n=44)$.

Regarding the Ling Test results (Table 2 \& Figure 2), all variables and forms of complexity show an average discrimination rate of $90 \%$. Although a rate decline is seen in the older age group, the higher complexity formats (on the phone and through the intercom) yield an average recognition rate of $65 \%$.

\begin{tabular}{|c|c|c|c|}
\hline & $\mathbf{6}$ to $\mathbf{1 5}$ years $\mathbf{( n = 7 )}$ & $\mathbf{2 0}$ to 45 years $(\mathbf{n}=\mathbf{2 5})$ & $\mathbf{5 0}$ to 86 years (n=12) \\
\hline Identification & 98 & 99 & 99 \\
\hline Whispered Voice & 95 & 96 & 93 \\
\hline While Moving & 95 & 100 & 88 \\
\hline With Background Noise & 97 & 96 & 90 \\
\hline Through A Door & 95 & 94 & 63 \\
\hline On The Phone & 70 & 63 & 66 \\
\hline Through The Intercom & 83 & 74 & 96 \\
\hline
\end{tabular}

Table 2: Ling Test. Average results of 3 age groups $(n=44)$.

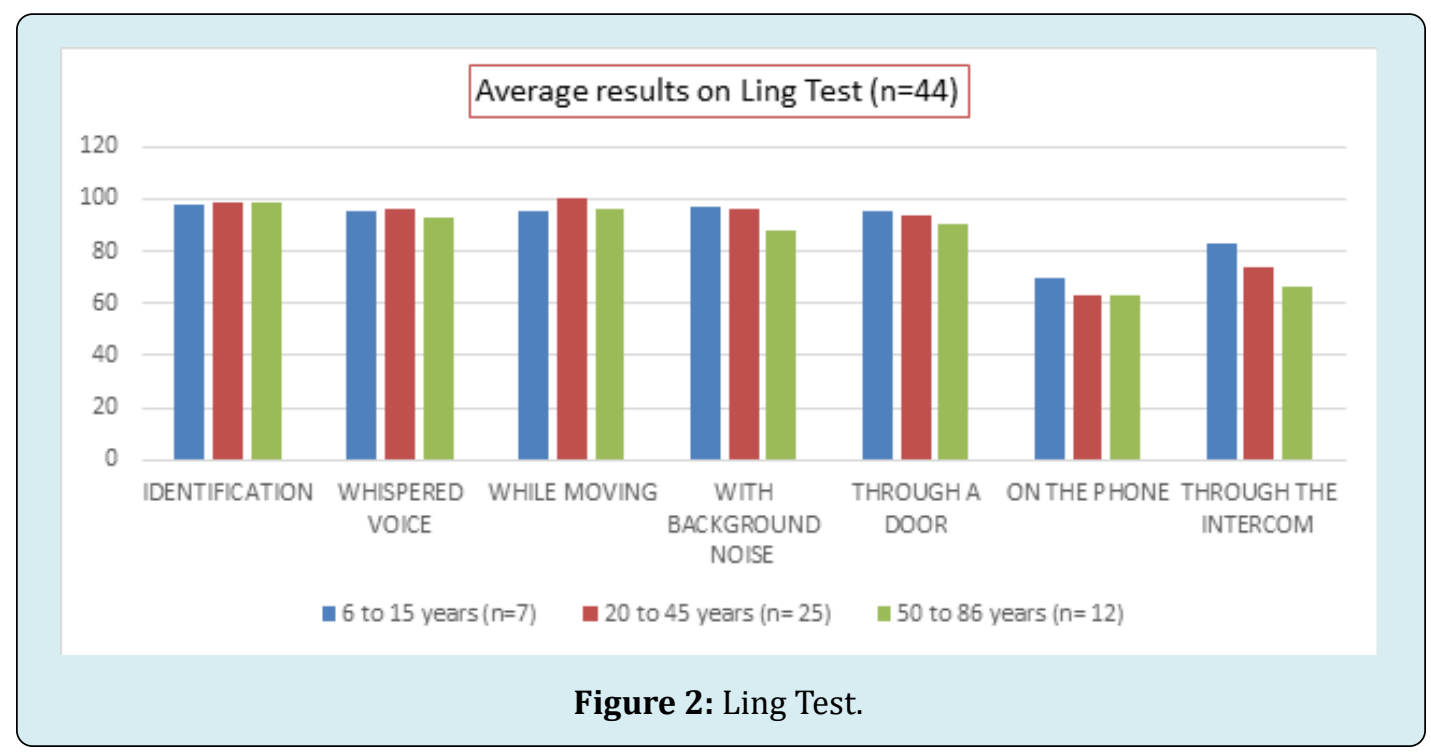

The results from the matrix of vowel recognition test (Table 3 \& Figure 3) demonstrate average rates of $90 \%$. As with the previous variable, a slight decrease is evident in the same last two forms (lower this time, with an average auditory discrimination rate of $80 \%$ ), including all age groups. 


\section{Otolaryngology Open Access Journal}

\begin{tabular}{|c|c|c|c|}
\hline & $\mathbf{6}$ to 15 years $(\mathbf{n = 7})$ & $\mathbf{2 0}$ to $\mathbf{4 5}$ years $(\mathbf{n = 2 5})$ & $\mathbf{5 0}$ to 86 years (n=12) \\
\hline Identification & 100 & 99 & 97 \\
\hline Whispered Voice & 97 & 93 & 90 \\
\hline While Moving & 97 & 99 & 87 \\
\hline With Background Noise & 100 & 97 & 90 \\
\hline Through A Door & 97 & 94 & 78 \\
\hline On The Phone & 87 & 81 & 72 \\
\hline Through The Intercom & 68 & 84 & 97 \\
\hline
\end{tabular}

Table 3: Vowel Test. Average results of 3 age groups $(n=44)$.

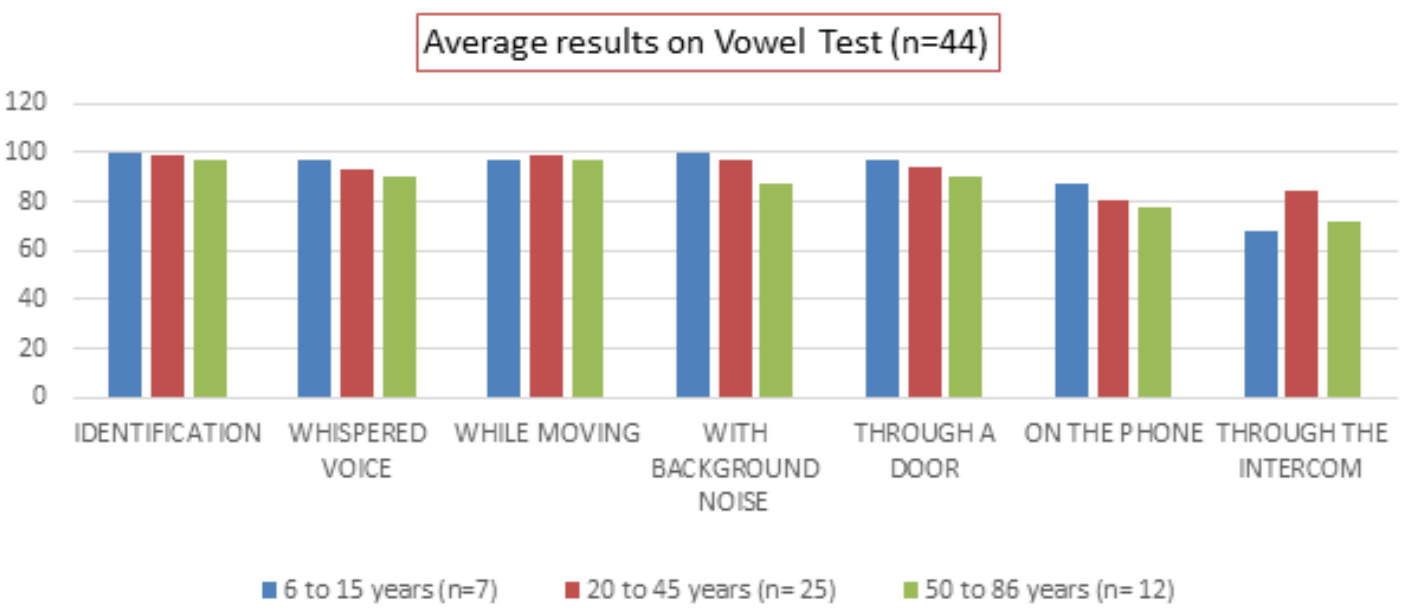

Figure 3: Vowel Test.

As regards the results from the matrix of medial consonant recognition test (Table 4 \& Figure 4), and including all forms of complexity, an average auditory discrimination rate of
$70 \%$ is revealed. The last three higher complexity formats show a decrease in the average rate to $60 \%$, regardless of the age group.

\begin{tabular}{|c|c|c|c|}
\hline & 6 to 15 years $(\mathbf{n}=\mathbf{7})$ & $\mathbf{2 0}$ to 45 years $(\mathbf{n}=\mathbf{2 5})$ & $\mathbf{5 0}$ to 86 years $(\mathbf{n = 1 2})$ \\
\hline Identification & 82 & 77 & 75 \\
\hline Whispered Voice & 83 & 67 & 63 \\
\hline While Moving & 79 & 70 & 67 \\
\hline With Background Noise & 80 & 62 & 64 \\
\hline Through A Door & 61 & 57 & 59 \\
\hline On The Phone & 62 & 51 & 58 \\
\hline Through The Intercom & 64 & 44 & 62 \\
\hline
\end{tabular}

Table 4: Consonant Test. Average results of 3 age groups $(n=44)$. 


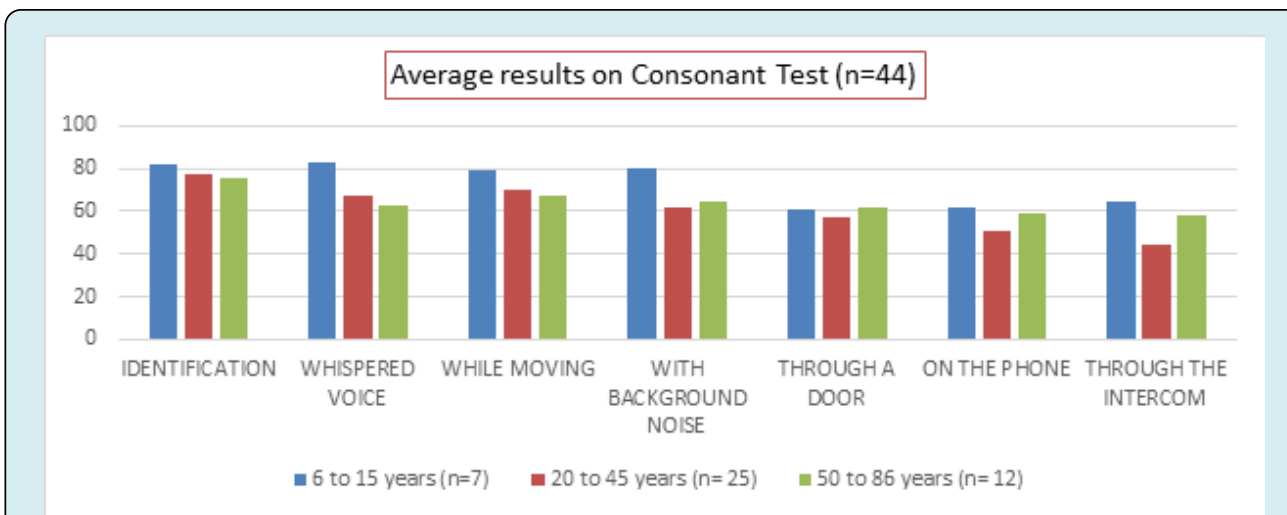

Figure 4: Consonant Test.

The results from the two-syllable word test (Table 5 \& Figure 5) demonstrate average rates of $70 \%$ and an overall decline as the formats become more complex, falling below an average of $50 \%$ (except the younger age group which maintains an average rate of $70 \%$ ).

\begin{tabular}{|c|c|c|c|}
\hline & $\mathbf{6}$ to $\mathbf{1 5}$ years $(\mathbf{n}=\mathbf{5})$ & $\mathbf{2 0}$ to $\mathbf{4 5}$ years $(\mathbf{n = 1 1})$ & $\mathbf{5 0}$ to 86 years $(\mathbf{n}=\mathbf{9})$ \\
\hline Identification & 86 & 77 & 82 \\
\hline Whispered Voice & 90 & 59 & 64 \\
\hline While Moving & 82 & 68 & 73 \\
\hline With Background Noise & 80 & 70 & 59 \\
\hline Through A Door & 76 & 54 & 56 \\
\hline On The Phone & 68 & 48 & 49 \\
\hline Through The Intercom & 67 & 41 & 70 \\
\hline
\end{tabular}

Table 5: Two-Syllable Word Test. Average results of 3 age groups $(n=25)$.

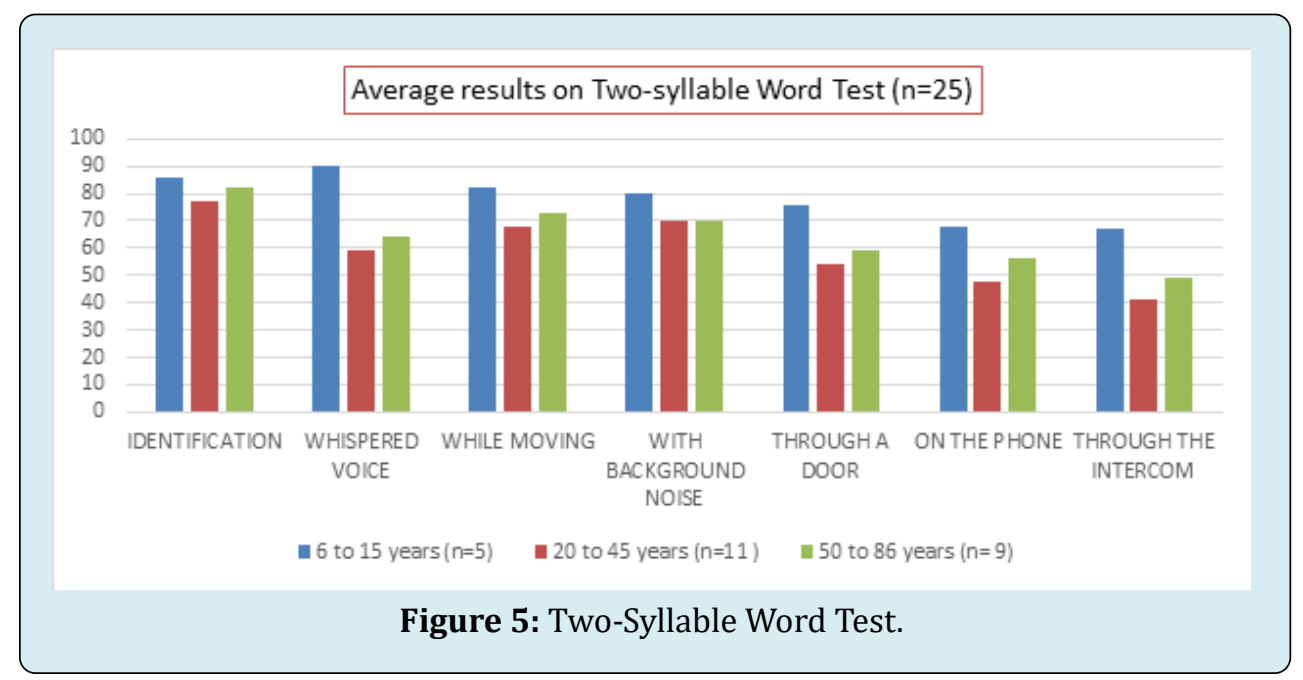

The last test, relative to the sentence stimuli variable (Table 6 \& Figure 6), demonstrates that the older age group exhibits an average rate of $80 \%$ in all levels of complexity. With respect to the rest of the groups, all variables of complexity and requirement show an average rate of $70 \%$. Two of the last variables presented to the younger age group exhibit a decreased rate, for the stimuli provided through a door and on the phone (yielding rates of $35 \%$ and $40 \%$ ). 


\section{Otolaryngology Open Access Journal}

\begin{tabular}{|c|c|c|c|}
\hline & $\mathbf{6}$ to 15 years $(\mathbf{n}=\mathbf{5})$ & $\mathbf{2 0}$ to $\mathbf{4 5}$ years $(\mathbf{n = 1 1})$ & $\mathbf{5 0}$ to 86 years (n=9) \\
\hline Identification & 67 & 80 & 86 \\
\hline Whispered Voice & 71 & 67 & 86 \\
\hline While Moving & 80 & 79 & 83 \\
\hline With Background Noise & 60 & 90 & 79 \\
\hline Through A Door & 35 & 58 & 74 \\
\hline On The Phone & 40 & 57 & 81 \\
\hline Through The Intercom & 73 & 52 & \\
\hline
\end{tabular}

Table 6: Sentence Test. Average results of 3 age groups $(n=25)$.

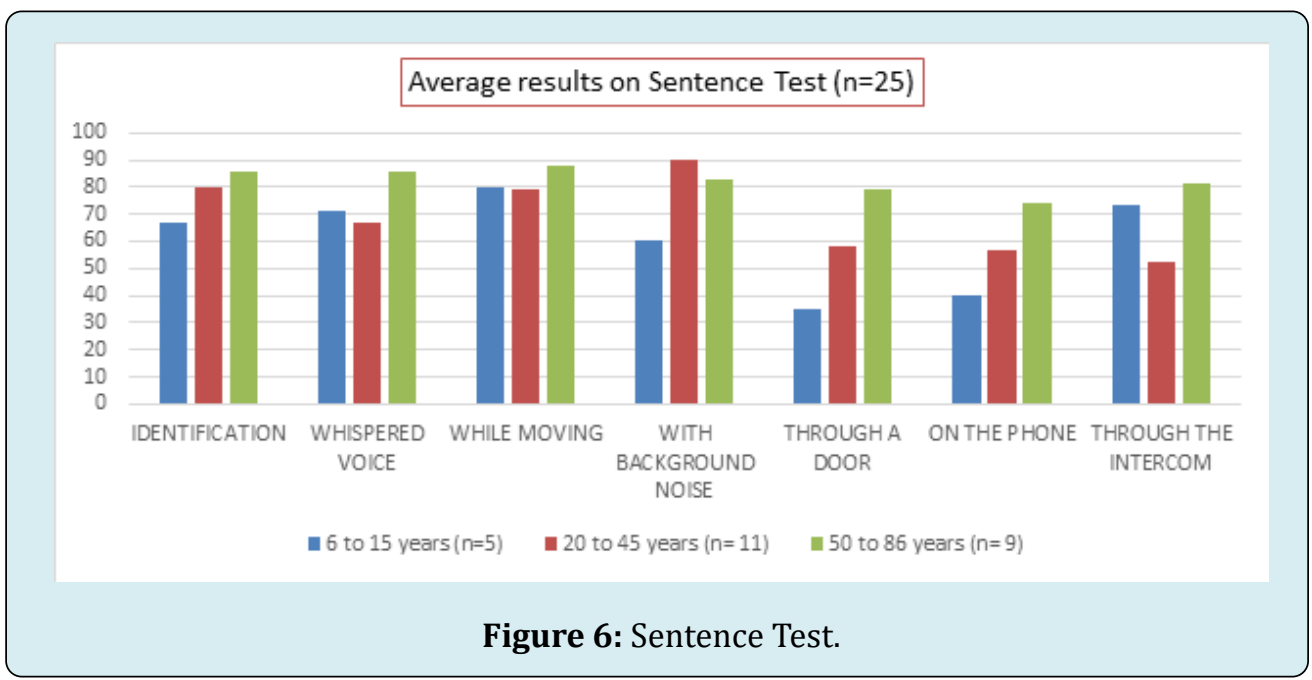

\section{Discussion}

The auditory benefits provided by the Cochlear Implant are consistent with the studies by Herman (2015). Based on the findings from that work, and although a late implantation reduces the performance, all implanted patients exhibit improvements in relation to their pre-implant status, being able to access the environmental sounds and to progressively participate in an auditory environment [5].

While this study aims at describing the behavior of patients to different auditory stimuli, it feeds back with the aforementioned work, showing improvements with respect to the auditory response and subsequent reintegration into society by using the implant in the daily life. As briefly stated in the introduction of this work, the hearing-impaired patients, without access to an intervention, would not be able to detect and recognize the different environmental sound stimuli, which would lead to difficulties in acquiring language as well as an abstract and formal code of communication.

In contrast to these cases and with reference to the data gathered from the results, it could be said that there is a notable response regarding the stimulation variables that were used, which are acoustic parameters for approaching hearing within the normal parameters. That is to say, the patients who undergo a cochlear implantation and a subsequent rehabilitation tend to improve in relation to the patients without access to this intervention. The early access to a cochlear implant and respective therapeutic strategies for auditory stimulation are elements that will allow patients not only to be connected to the world of sound, but also to develop and favor their linguistic skills.

With respect to the older age group, the investigation findings show that they exhibit response rates to stimulation variables that are consistent with the rest of the groups, which might imply a tendency for an improved auditory discrimination quality. Hearing loss in elderly people leads to negative consequences at the emotional and psychosocial level, making them isolated, which in the long run can turn into an emotional disorder and/or cognitive decline that might reduce their quality of life [7].

It could be thought that the implantation and subsequent auditory rehabilitation after one year of using the cochlear implant will facilitate positive changes and an improved quality of life for those adults, allowing them to access the frequencies in the word zone and giving them the chance for social reintegration. The findings and conclusions from the 
present work give rise to new questions for future research regarding the benefits of and limitations to accessing a Cochlear Implant, as well as the development of increasingly appropriate strategies for rehabilitation.

\section{Conclusion}

The findings reported here are a valuable descriptive contribution, as they include the implementation of novel variables and forms of approach in a constantly-advancing field like auditory rehabilitation post-Cochlear Implant. Considering it is a growing therapeutic process which requires constant implementation, it is essential to acknowledge and point out the influence of the different stimulation variables, as well as their potential forms of complexity and requirement according to the age group. Furthermore, these variables and situations of complexity are comparable to the different challenges these subjects might face in the daily life.

\section{References}

1. Liceda ME, Taglialegne N, Neustadt N, Camareri B, Silva MA, et al. (2014) Programa nacional de fortalecimiento de la detección precoz de enfermedades congénitas. Pesquisa Neonatal Auditiva. Junio pp: 7.

2. Perelló J, Tortosa F (1992) Sordera profunda, bilateral, prelocutiva. ed, Fondo Editorial; 1992.

3. Amat MT (2011) Los mayores y el implante coclear. Federación AICF.

4. Diamante V (2004) Otorrinolaringología y afecciones conexas. Segunda edición, El ateneo editorial.

5. Herman R, Sterin M, Filippi M, López A, Redivo A (2015) Performance and quality of life in adolescent and adult patients with prelingual cochlear implant. Revista Federación Argentina de Sociedades de Otorrinolaringología 22(2): 58-62.

6. Flores Beltrán L, Villalobos P (2006) Los problemas de la audición en la edad preescolar. Trillas.

7. Roldan B (2013) Speech therapy rehabilitation and its role in the treatment of the deaf adult. Integration pp: 6-8. 